\title{
Quantification of Opioids in Urine using an Aptamer-based Free- solution Assay
}

Michael N. Kammer ${ }^{[a]}$, Amanda Kussrow ${ }^{[a]}$, Ilavarasi Gandhi ${ }^{[b]}$, Rafal Drabek ${ }^{[b]}$, Robert H. Batchelor ${ }^{[b]}$, George W. Jackson ${ }^{[b]}$, and Darryl J. Bornhop ${ }^{[a]^{*}}$

[a] Dr. M. N. Kammer, Dr. A. Kussrow, Prof. D. J. Bornhop, Department of Chemistry and Vanderbilt Institute of Chemical Biology, Vanderbilt University, Nashville, TN, 37235 USA. E-mail: darryl.bornhop@vanderbilt.edu

[b] I. Gandhi, R. Drabek, R. Batchelor, Dr. G. Jackson, Base Pair Biotechnologies, Pearland, Texas, 77584 USA

Table of Contents

1. The Compensated Interferometric Reader ........................................ S-2

1.1. Syringe Pump Setup........................................................... S-2

1.2. Droplet Train Generation .................................................... S-2

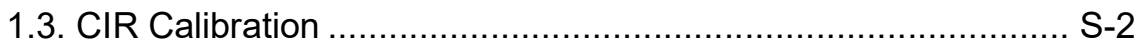

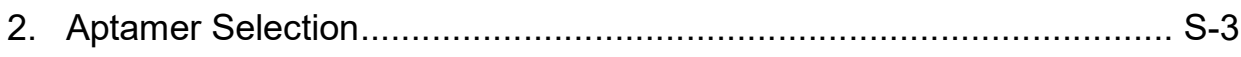

3. Free Solution Assay Methods ..................................................... S-3

3.1. Aptamer solution preparation ........................................... S-3

3.2. Opiate target solution preperation ........................................ S-3

3.3. Aptamer characterizations …................................................ S-3

4. Opioid Quantification.................................................................. S-5

5. Cross-Reactivity Masurements .................................................. S-7

6. Quantification of Unknowns........................................................ S-8

7. Pharmacokinetic Modeling .......................................................... S-9

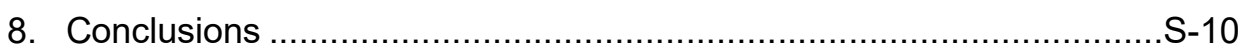

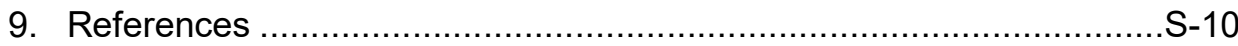




\section{The Compensated Interferometric Reader}

The compensated interferometric reader (CIR), illustrated in Figure S1, consists of a compensated interferometer ${ }^{[1]}$, a droplet generator and a syringe pump.

1.1 Syringe Pump Setup: A Chemyx ${ }^{\circledR}$ Nexus 3000 Syringe pump pulling a Hamilton Gastight ${ }^{\circledR}$ 1001 syringe provides constant flow through the capillary at $10 \mu \mathrm{L} / \mathrm{min}$. The syringe was interfaced to the capillary using a LabSmith Luer-Lock to capillary adaptor. Using a Hamilton syringe with an inner diameter of $4.610 \mathrm{~mm}$ and volume of $1000 \mu \mathrm{L}$ gives a total flow time of about 100 minutes.

1.2 Droplet Train Generation: The Mitos Dropix was interfaced to the interferometer so that droplet trains were formed directly in the capillary (350 $\mu \mathrm{m}$ OD / $250 \mu \mathrm{m}$ ID, Polymicro, USA), allowing a single section of capillary to serve as both the reader cell and the transfer line. Droplet trains were produced by a sample hook/capillary moving up and down between two "reservoirs" while the pump pulls fluid. One of the reservoirs was an open tray containing the oil (Flourinert FC-40, Sigma-Aldrich) used to separate the droplets, the other was a PEEK tray consisting of 24 bottomless wells where the sample and reference solutions reside. Hook sample-well dwell time and solution flow rate determines droplet volume and spacing. The Dropix system was programmed using the built-in software.

Sample and reference solutions were loaded into adjacent wells in a Dropix sample well tray $(20 \mu \mathrm{L}$ of each). A single determination consists of a droplet train of $1000 \mathrm{~nL}$ of sample and reference solutions separated by $40 \mathrm{~nL}$ of oil. The first sample/reference pair was preceded by $4 \times 4 \mu \mathrm{L}$ droplets of PBS, each separated by $100 \mathrm{~nL}$ of oil. For all determinations using the CIR, the sample/reference pairs were introduced five times for a total of 10 droplets. Following the analysis of each group of sample/reference droplet pairs a $500 \mathrm{~nL}$ droplet of oil and $2 \times 4 \mu \mathrm{L}$ droplets of PBS separated by $100 \mathrm{~nL}$ of oil was used to rinse and prepare the capillary for the next sample/reference pair. An entire droplet train, consisting of all six sample pairs and the required rinses, takes about 14 minutes to run through the CIR. Assays requiring more than 6 determinations were performed by running multiple trays sequentially. After an entire tray was run, the capillary was rinsed with PBS for 3 minutes before beginning the next tray.

1.3 CIR Calibration: Device performance and instrument response was evaluated using solutions containing $0,0.125,0.25,0.5,1$, and $2 \mathrm{mM}$ glycerol in PBS in $50 \%$ urine / 50\% PBS. PBS serves as the reference sample. Using the calibration curve we establish that the response function of the instrument is $\sim 0.110$ radians $/ \mathrm{mM}$ glycerol, the reproducibility of replicate measurements (standard deviation) for like glycerol concentrations is $<0.012$ radians, and the limit of quantification LOQ values $<0.33 \mathrm{mM}$. The LOD was determined by measuring $\sim 3$ seconds of baseline noise of the phase shift and was $\sim 0.111 \mathrm{mM}$

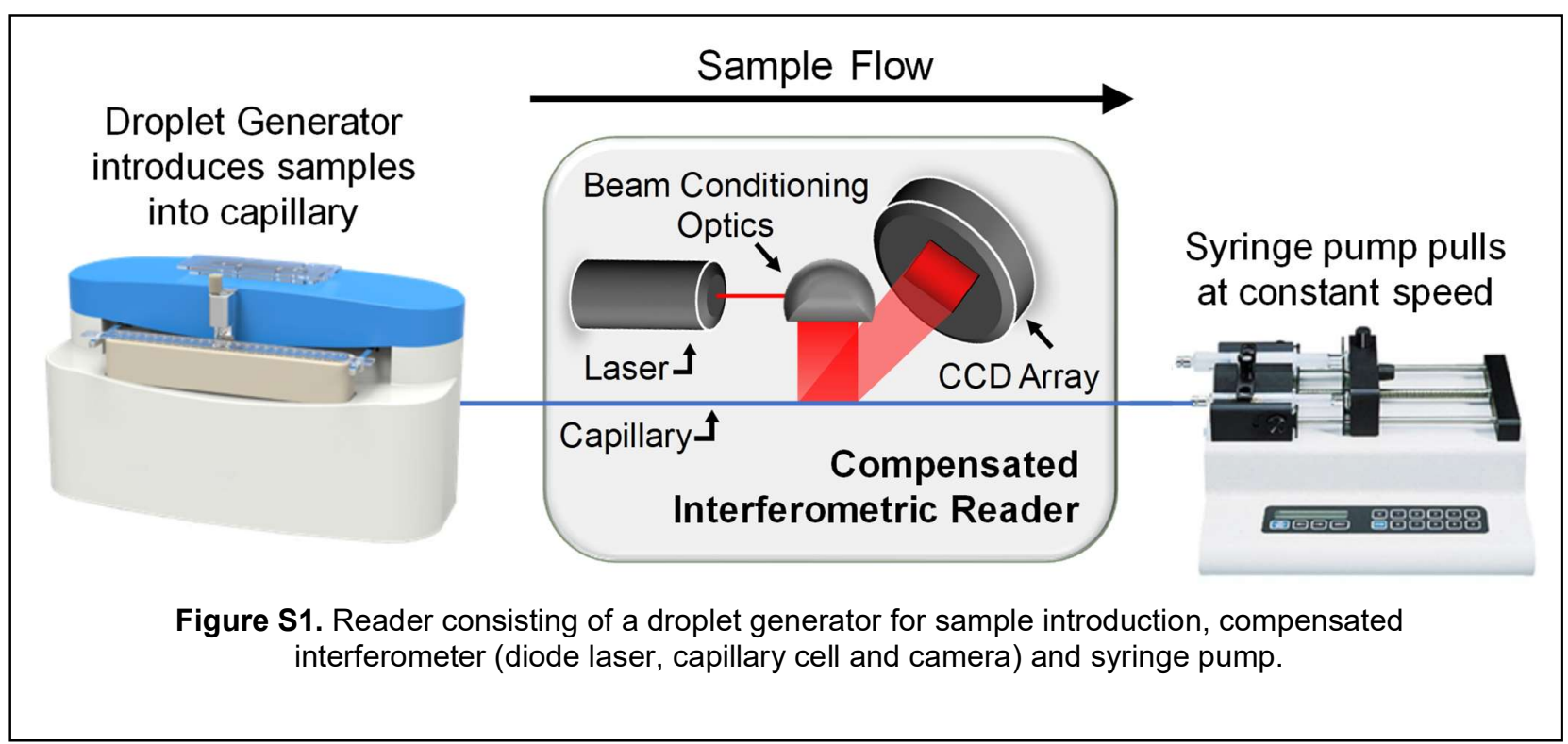




\begin{tabular}{cccccc}
\multicolumn{6}{l}{ Table S1. Opioid targets and their dilution concentrations. } \\
\hline A) Target & $\begin{array}{c}\text { B) Molecular } \\
\text { Weight }\end{array}$ & $\begin{array}{c}\text { C) Stock } \\
\text { Concentration }\end{array}$ & $\begin{array}{c}\text { D) Working } \\
\text { Concentration }\end{array}$ & $\begin{array}{c}\text { E) Dilution } \\
\text { Volume of } \\
\text { Target }\end{array}$ & $\begin{array}{c}\text { F) Dilution } \\
\text { Volume of 1\% } \\
\text { Methanol/PBS }\end{array}$ \\
\hline Oxycodone & $315.36 \mathrm{~g} / \mathrm{mol}$ & $3.17 \mathrm{mM}$ & $31.7 \mu \mathrm{M}$ & $6.33 \mu \mathrm{L}$ & $993.67 \mu \mathrm{L}$ \\
Noroxycodone $\mathrm{HCl}$ & $337.80 \mathrm{~g} / \mathrm{mol}$ & $2.96 \mathrm{mM}$ & $29.6 \mu \mathrm{M}$ & $6.44 \mu \mathrm{L}$ & $993.56 \mu \mathrm{L}$ \\
Hydrocodone & $299.36 \mathrm{~g} / \mathrm{mol}$ & $3.34 \mathrm{mM}$ & $29.9 \mu \mathrm{M}$ & $6.70 \mu \mathrm{L}$ & $993.30 \mu \mathrm{L}$ \\
Norhydrocodone $\mathrm{HCl}$ & $321.80 \mathrm{~g} / \mathrm{mol}$ & $3.11 \mathrm{mM}$ & $31.1 \mu \mathrm{M}$ & $6.43 \mu \mathrm{L}$ & $993.57 \mu \mathrm{L}$ \\
Fentanyl & $336.47 \mathrm{~g} / \mathrm{mol}$ & $2.97 \mathrm{mM}$ & $29.7 \mu \mathrm{M}$ & $6.73 \mu \mathrm{L}$ & $993.27 \mu \mathrm{L}$ \\
Norfentanyl Oxalate & $322.36 \mathrm{~g} / \mathrm{mol}$ & $3.10 \mathrm{mM}$ & $31.0 \mu \mathrm{M}$ & $6.45 \mu \mathrm{L}$ & $993.55 \mu \mathrm{L}$ \\
Cortisol & $362.46 \mathrm{~g} / \mathrm{mol}$ & $2.76 \mathrm{mM}$ & $27.6 \mu \mathrm{M}$ & $7.24 \mu \mathrm{L}$ & $992.76 \mu \mathrm{L}$ \\
\hline
\end{tabular}

glycerol. Based upon our past experience, this sensitivity is more than adequate to perform free-solution molecular interaction studies. ${ }^{[2]}$

\section{Aptamer selection}

All opioid aptamers were selected by Base Pair Biotechnologies, Inc. (Pearland, TX, USA) using a modification of the SELEX method of Nutiu et al. ${ }^{[3]}$ To avoid the potential risk for opioid contamination in "normal" pooled human urine, an ersatz urine formulation comprising 1X PBS, $300 \mathrm{mM}$ urea, $6 \mathrm{mM}$ creatinine, $0.05 \%$ Tween-20, and $1 \mathrm{mM} \mathrm{MgCl}_{2}$ was used. After multiple rounds of positive and negative selection, the enriched aptamer pools were sequenced using an lon Torrent PGM next generation sequencer (Thermo Fisher), and for each target, bioinformatics analysis was used to choose aptamers for synthesis and functional screening in the FSA assay.

\section{Free Solution Assay Methods}

3.1 Aptamer solution preparation: The aptamer stock solutions were prepared by reconstituting the aptamer dried pellet to a concentration of $100 \mu \mathrm{M}$ in a modified Phosphate Buffered Saline (PBS) containing $1 \mathrm{mM} \mathrm{MgCl}_{2}, 10 \mathrm{mM}$ Tris $\mathrm{HCl}$, and $0.1 \mathrm{mM}$ EDTA with $\mathrm{pH} 7.5$. All further dilutions used this PBS formulation. The stock aptamer solution was then diluted to $1 \mu \mathrm{M}$ (working concentration) in PBS. Once diluted to the working concentration (Table S1), the aptamers were refolded by heating the solution to $90^{\circ} \mathrm{C}$ for 5 minutes in a water bath, then cooled to room temperature for 15 minutes. This process ensures the aptamers were in their desired conformation. For cross reactivity measurements (detailed below), stock aptamer solution was diluted to $2 \mu \mathrm{M}$ before refolding.

3.2 Opiate target solution preparation: The six opioid and metabolite targets and cortisol listed in Table S1 were obtained from Sigma-Aldrich at $1 \mathrm{mg} / \mathrm{ml}$ in methanol. For all targets, stock solutions were prepared at a concentration of $2.7-3.3 \mathrm{mM}$. Care was taken to insure the concentration of the target samples stayed below the $1 \mathrm{mM}$ aqueous solubility limit. To prepare analysis samples, $10 \mu \mathrm{L}$ of the opioid standard solution was added to $990 \mu \mathrm{L}$ of PBS, creating working solutions of 27 and $32 \mu \mathrm{M}$ (Table S1, Column D). The resulting solvent composition of the working solutions was $99 \%$ PBS and $1 \%$ methanol. Next, a volume of the working solution (Table S1, Column E) was diluted to $200 \mathrm{nM}$ with $1 \%$ methanol in PBS. The 1\% methanol in PBS solution was kept constant across all target dilutions to ensure that solutions in the free-solution measurements were index matched.

3.3 Aptamer characterizations: Binding affinity assays were performed in an end-point format: First, a $100 \mathrm{nM}$ solution of each target was prepared in 50\% Urine / 49.5\% PBS / 0.5\% Methanol by adding $100 \mu \mathrm{L}$ of the $200 \mathrm{nM}$ target (prepared above) to $100 \mu \mathrm{L}$ of pooled human urine (Valley 


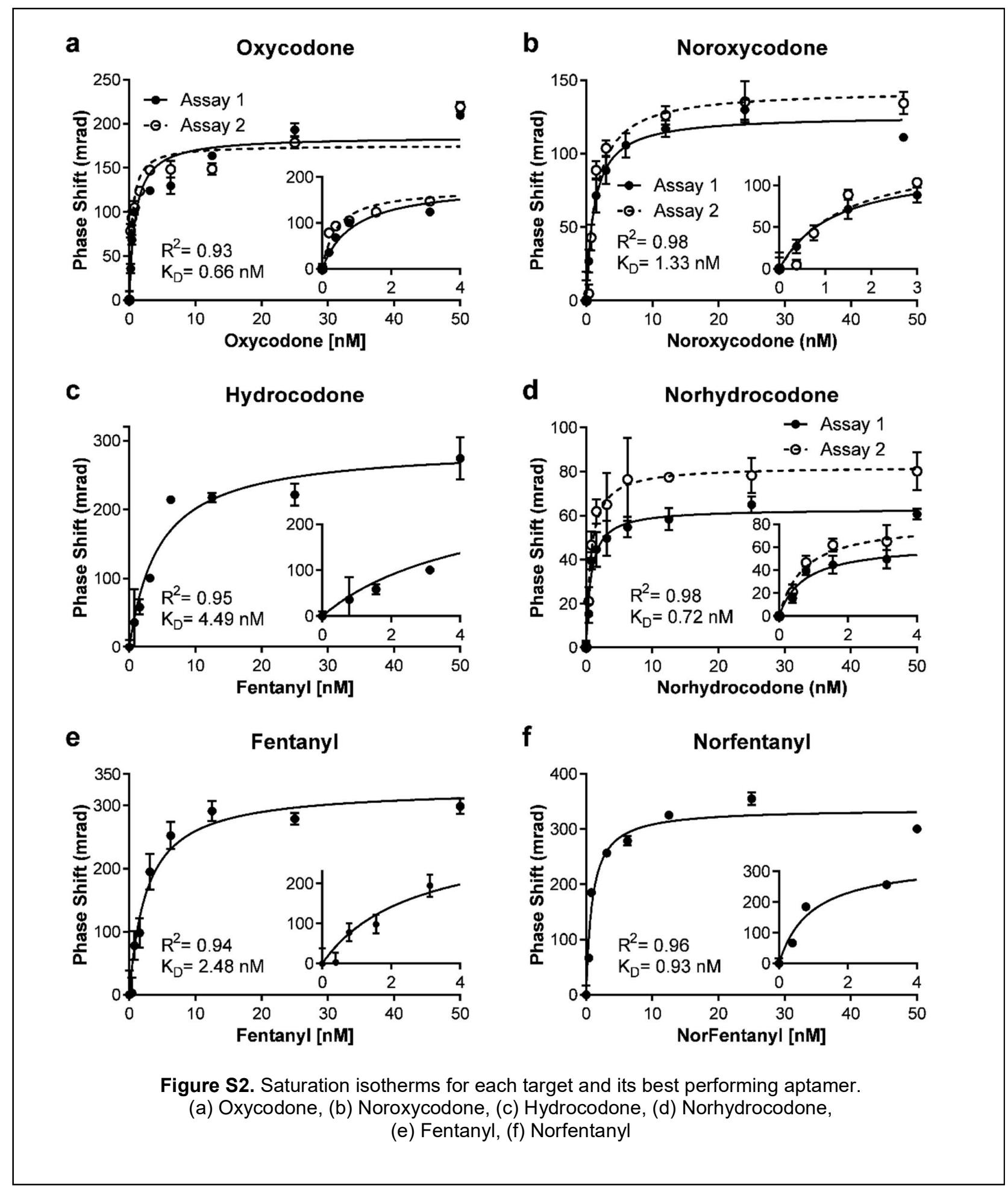


biomedical). Second, a 7-point serial dilution series was prepared from the $100 \mathrm{nM}$ target solution by diluting the solution in half at each step with $50 \%$ urine / 49.5\% PBS / 0.5\% methanol. This dilution series resulted in 7 concentrations ranging from $100-0.780 \mathrm{nM}$. A "zero" concentration consisted of $100 \mu \mathrm{L}$ of $50 \%$ urine / $49.5 \%$ PBS / $0.5 \%$ methanol. The corresponding aptamer to the target was then diluted from the $1 \mu \mathrm{M}$ working concentration to give a solution of $2 \mathrm{nM}$ aptamer in $50 \%$ Urine / $50 \%$ PBS. An RI-matched control solution was then prepared with $50 \%$ urine and $50 \%$ PBS. For each concentration in the target dilution series, $10 \mu \mathrm{L}$ of the diluted target was combined with $10 \mu \mathrm{L}$ of the $2 \mathrm{nM}$ aptamer to produce the binding sample, while $10 \mu \mathrm{L}$ of the diluted target was combined with $10 \mu \mathrm{L}$ of the RI-matched control solution to produce the reference sample. The final aptamer concentration in the binding samples was $1 \mathrm{nM}$, and the final target concentration ranged from $0-50 \mathrm{nM}$. For each concentration, the binding and reference samples were measured with the CIR in quintuplicate. The averaged phase shift for 5 replicates was plotted vs. target concentration (Figure S2). Dissociation constants were then calculated by fitting the data to a single-site saturation isotherm using Graphpad Prism ${ }^{\mathrm{TM}}$ according to the equation:

$$
y=\frac{B_{\max } \cdot X}{K_{D}+X}
$$

Figure $\mathbf{S 2}$ shows the saturation isotherm for all six opioid target-aptamer $\mathrm{K}_{\mathrm{D}}$ determinations, and these results are presented in Table S2.

Day-to-day reproducibility was evaluated for three targets (Oxycodone, Noroxycodone, and Norhydrocodone) by rerunning the assay on subsequent days. For these three determinations, we calculated the percent difference (mean/standard deviation) for both signal magnitude $\left(B_{\max }\right)$ and affinity $\left(K_{D}\right)$, obtaining a value of $13.6 \%$ for $B_{\max }$ and $24.5 \%$ for $K_{D}$. Based on these results, additional $K_{D}$ determinations were deemed unnecessary for hydrocodone, fentanyl, and norfentanyl.

\section{Opioid Quantification}

Calibration curves were prepared by creating a dilution series of the target (opioid) at concentrations ranging from $0-200 \mathrm{nM}$ in 50\% Urine / 49.5\% PBS / 0.5\% Methanol. Aptamer solutions of $2 \mu \mathrm{M}$ were prepared in $50 \%$ Urine / $50 \%$ PBS. The binding sample was prepared by combing $10 \mu \mathrm{L}$ of the target each concentration of the target dilution series with $10 \mu \mathrm{L}$ of $2 \mu \mathrm{M}$ aptamer solution. To produce the reference solution, $10 \mu \mathrm{L}$ of each target dilution was combined with $10 \mu \mathrm{L}$ of the RI-matching control solution. The final aptamer concentration in the binding samples was $1 \mu \mathrm{M}$, and the final target concentration ranged from $0-100 \mathrm{nM}$.

Table S2. Performance summary for opioid assays.

\begin{tabular}{|c|c|c|c|c|c|c|}
\hline Target & $\underset{(n M)}{K d}$ & $\begin{array}{l}\text { LOD } \\
\text { (pg/ml) }\end{array}$ & $\begin{array}{l}\text { LOQ } \\
\text { (pg/ml) }\end{array}$ & $\begin{array}{c}\text { Quantification } \\
\text { Error }\end{array}$ & $\begin{array}{c}\text { Total Off-Target } \\
\text { Signal[a] }\end{array}$ & $\begin{array}{l}\text { Detected } \\
\text { above LOQ }\end{array}$ \\
\hline Fentanyl & 2.48 & 45 & 63 & $5.5 \%$ & $6 \%$ & $\mathrm{n} / \mathrm{a}$ \\
\hline Norfentanyl & 0.93 & 81 & 94 & $5.6 \%$ & $13 \%$ & $(5 \%)$ \\
\hline Oxycodone & 0.66 & 28 & 44 & $4.4 \%$ & $0 \%$ & $\mathrm{n} / \mathrm{a}$ \\
\hline Noroxycodone & 1.33 & 72 & 183 & $2.4 \%$ & $8 \%$ & $\mathrm{n} / \mathrm{a}$ \\
\hline Hydrocodone & 4.49 & 45 & 159 & $1.6 \%$ & $5 \%$ & $\mathrm{n} / \mathrm{a}$ \\
\hline Norhydrocodone & 0.72 & 42 & 84 & $4.1 \%$ & $11 \%$ & $(6 \%)$ \\
\hline
\end{tabular}

[a] Determined versus the target's non-cognate molecule

[b] Numbers in parentheses are signal above the LOQ, calculated as (Off-target Signal - LOQ) / (Maximum Target Signal - LOQ) 
a

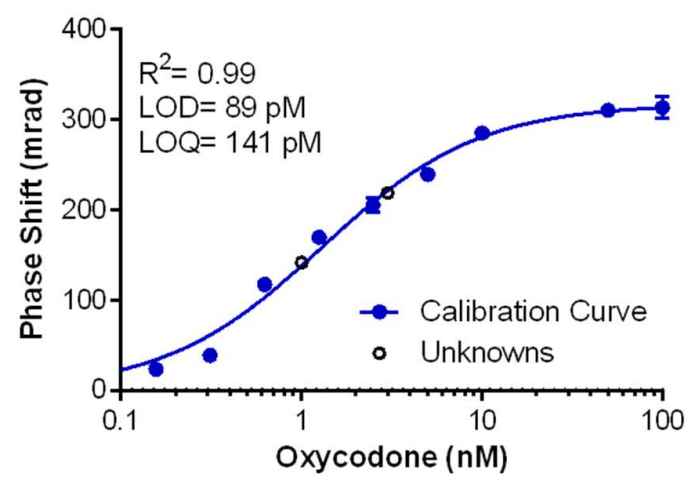

C

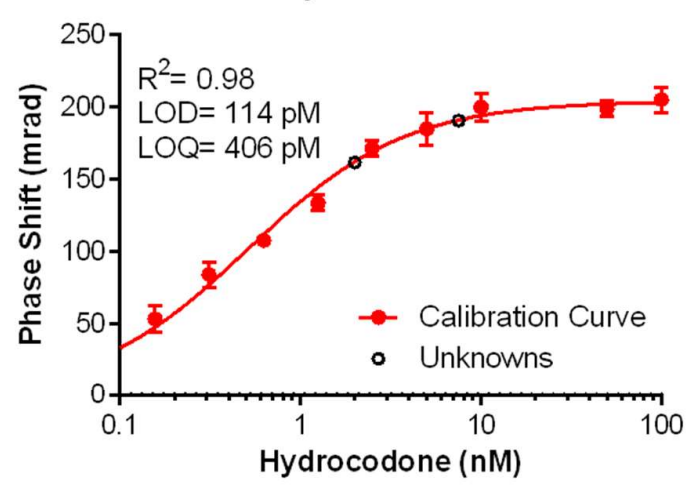

e

Fentanyl

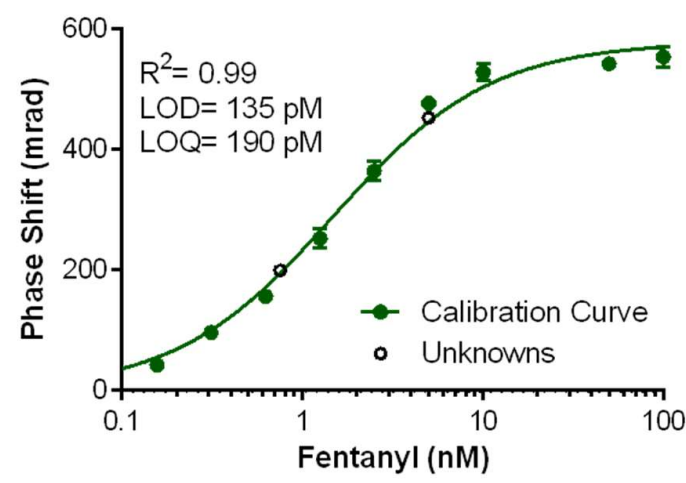

Noroxycodone

b

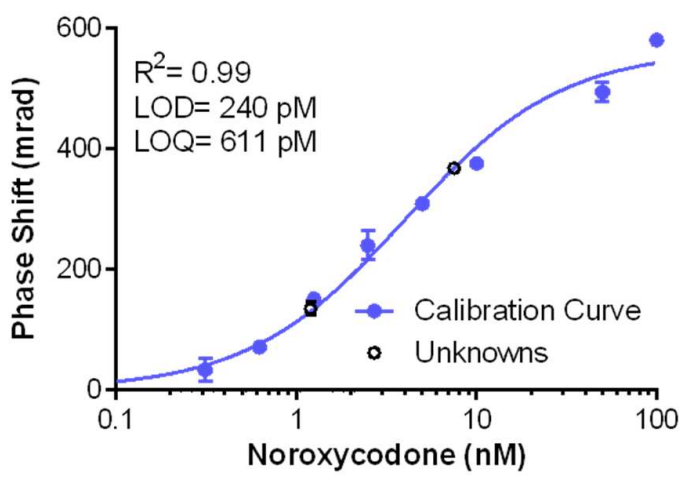

d

Norhydrocodone

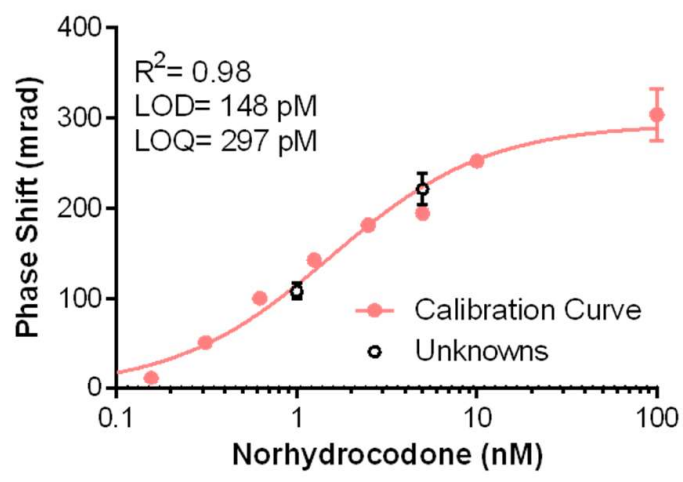

f

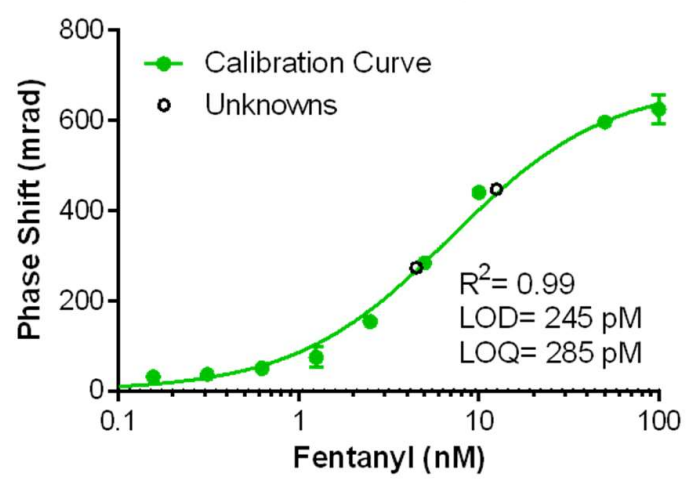

Figure S3. Calibration curves for the six targets. (a) Oxycodone, (b) Noroxycodone, (c) Hydrocodone, (d) Norhydrocodone, (e) Fentanyl, (f) Norfentanyl 


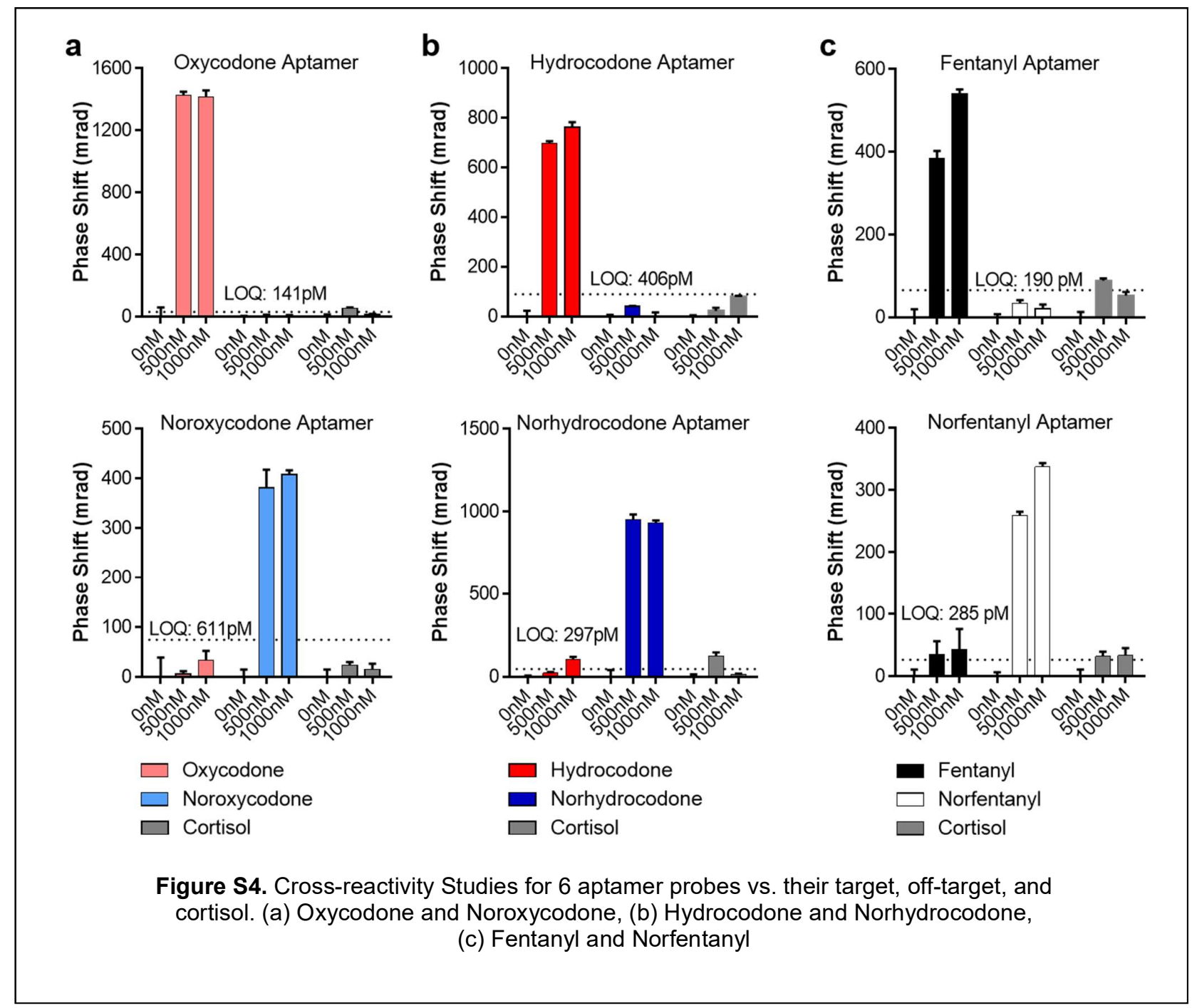

The phase shift between binding and reference sample was quantified with CIR by fitting the response to a saturation isotherm. The slope in the linear region of this curve was used to calculate the LOD ( $3 \times \sigma$ of the instrument baseline noise/slope) and the LOQ ( $3 \times \sigma$ of replicate measurements/slope). Figure $\mathbf{S} 3$ shows the assay calibration curves for all 6 opioid targets.

\section{Cross-Reactivity Measurements}

Specificity studies were performed for each of the aptamers to the target metabolite and cortisol. For example, the aptamer for oxycodone was tested for non-specific binding to noroxycodone and cortisol, and binding of the noroxycodone aptamer to oxycodone and cortisol.

Binding samples consisted of a $2000 \mathrm{nM}$ target solution prepared from the working concentration (Table S1, Column D), in 50\% Urine / 49\%PBS / 1\% methanol. A $50 \mu \mathrm{L}$ volume of this solution was further diluted in $50 \mu \mathrm{L}$ of $50 \%$ Urine / 49\% PBS / 1\% methanol to produce a $1000 \mathrm{nM}$ solution. A solution containing $2000 \mathrm{nM}$ aptamer in 50\% Urine / 50\% PBS was prepared from the stock aptamer solution. Then, $10 \mu \mathrm{L}$ of the aptamer was incubated with $10 \mu \mathrm{L}$ of $0 \mathrm{nM}, 1000 \mathrm{nM}$, and $2000 \mathrm{nM}$ of the target, resulting in final solutions containing $1 \mu \mathrm{M}$ aptamer and $1000 \mathrm{nM}, 500 \mathrm{nM}$, and $0 \mathrm{nM}$ target in a solution of $50 \%$ urine $/ 49.5 \%$ PBS / $0.5 \%$ methanol. 


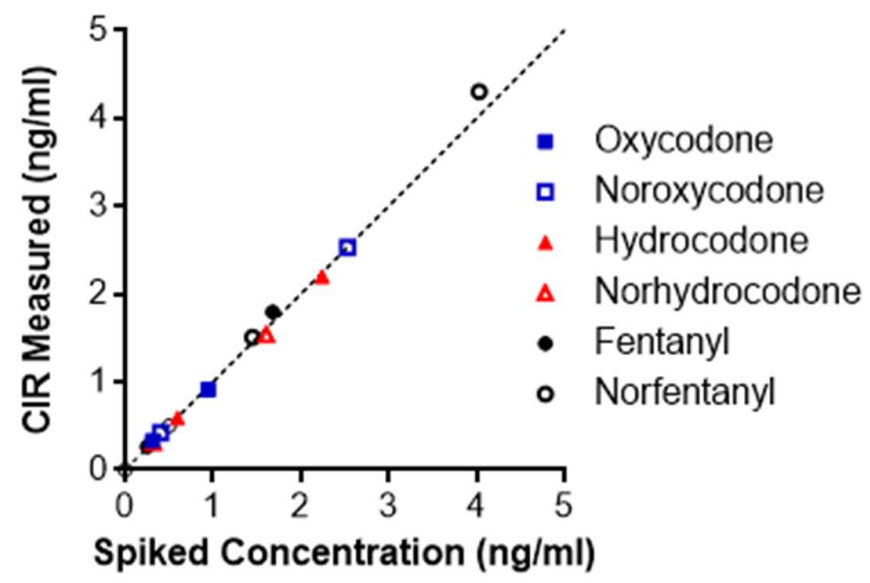

Figure S5. FSA-CIR quantification of unknowns, providing $<5 \%$ error for all species in spiked unknown measurements.

Reference samples were prepared by adding $10 \mu \mathrm{L}$ of a $50 \%$ urine / $50 \%$ PBS solution to $10 \mu \mathrm{L}$ of 0 $\mathrm{nM}, 1000 \mathrm{nM}$, and $2000 \mathrm{nM}$ of the target, giving final solutions containing $1000 \mathrm{nM}, 500 \mathrm{nM}$, and $0 \mathrm{nM}$ target in $50 \%$ urine / $49.5 \%$ PBS / $0.5 \%$ meth.

Sample-reference pairs were measured with CIR with the results from these determinations presented in Figure S4. In all cases, the response for the aptamers' designated targets was quite large, while the signal for the off-target species and cortisol were at or below the assay's LOQ. The dotted line in Figure $\mathbf{S 4}$ represents the LOQ values for each aptamer assay.

\section{Quantification of Unknowns}

Test "unknowns" were prepared by spiking blank human urine with the opioid target. Then, $10 \mu \mathrm{L}$ of the unknown was combined with $10 \mu \mathrm{L}$ of $2 \mu \mathrm{M}$ aptamer probe in PBS to create the binding sample. The reference sample was created by combining $10 \mu \mathrm{L}$ of the unknown sample with $10 \mu \mathrm{L}$ of PBS devoid of aptamer. All unknowns were prepared by a lab member other than the "operator," with the operator blinded to the sample's true concentration. The signal for the unknowns were fit to the calibration curve to determine the concentration. All unknowns were measured within the linear region of the calibration

Table S3. Quantification of Unknowns (values in $\mathrm{ng} / \mathrm{ml}$ ).

\begin{tabular}{cccccc}
\hline \multirow{2}{*}{ Target } & \multicolumn{2}{c}{ Unknown 1 } & \multicolumn{2}{c}{ Unknown 2 } & \multirow{2}{*}{ Average Error } \\
\cline { 2 - 5 } & Spiked & Measured & Spiked & Measured & \\
\hline Fentanyl & 0.25 & 0.26 & 1.68 & 1.80 & $5.5 \%$ \\
Norfentanyl & 1.45 & 1.51 & 4.03 & 4.31 & $5.6 \%$ \\
Oxycodone & 0.32 & 0.33 & 0.95 & 0.91 & $4.4 \%$ \\
Noroxycodone & 0.41 & 0.42 & 2.53 & 2.53 & $2.4 \%$ \\
Hydrocodone & 0.60 & 0.59 & 2.25 & 2.20 & $1.6 \%$ \\
Norhydrocodone & 0.32 & 0.31 & 1.61 & 1.54 & $4.1 \%$ \\
\hline
\end{tabular}


curves. The percent error was calculated as $\%$ error $=\frac{\text { measured-true }}{\text { true }}$. The unknowns are plotted as open circles in overlaid upon the calibration curves in Figure S3. The results are summarized in Table S3 and Figure S5 and illustrate the excellent correlation between the true and unknown values.

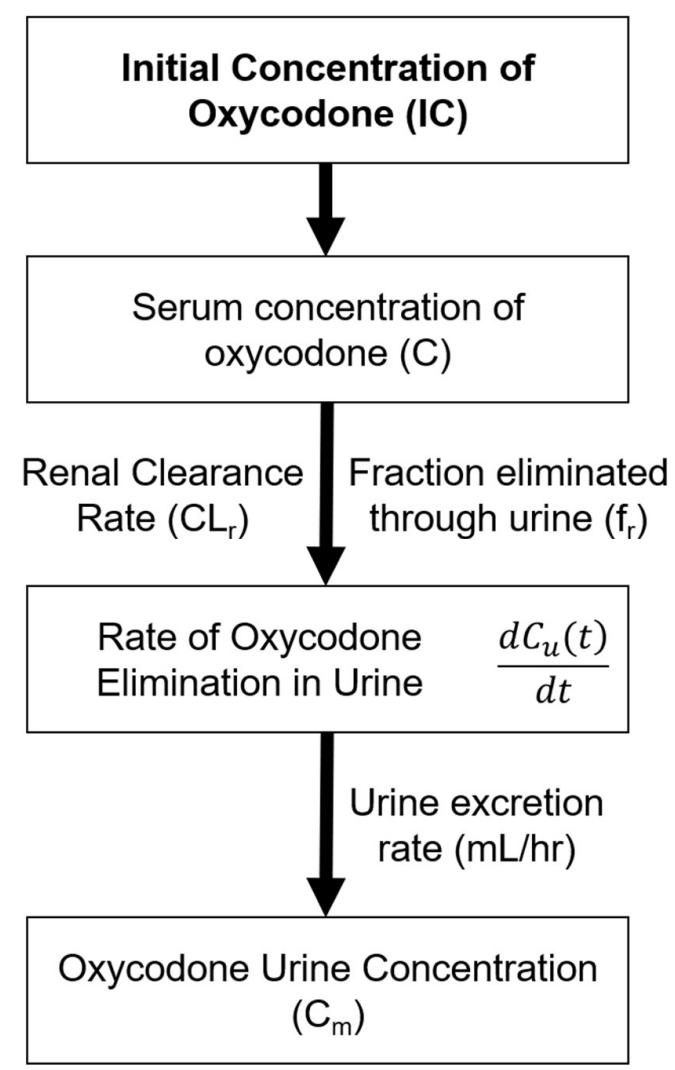

Figure S6. Single metabolite model of drug elimination.

\section{Pharmacokinetic Modelling}

Oxycodone and noroxycodone concentration-time profiles were calculated using a single-metabolite model where the primary opioid is eliminated via two pathways: 1) directly through urine excretion and 2 ) by metabolism to a single metabolite and then excretion through urine. As shown below, to calculate the urine concentration of a drug (for example, oxycodone), it is necessary to first determine the serum concentration over time. This is calculated using a first-order decay, equation $2 .{ }^{[4]}$

$$
C(t)=I C e^{-k t}
$$

Where $I C$ is the initial concentration and $k$ is the elimination rate constant. We chose two cases in our calculations for the initial concentration (IC). 1) The recommended analgesic doses $\left(25 \mathrm{ng} / \mathrm{mL}^{[5]}\right.$ and $120 \mathrm{ng} / \mathrm{mL}^{[6]}$ ) for a newborn, and 2) a high concentration induced by illicit opiate use by the mother (300 $\mathrm{ng} / \mathrm{ml}$ and the $2000 \mathrm{ng} / \mathrm{ml})$. $^{[7]}$

Equation 3 was used to determine $k$ from the drug's half-life $\left(t_{1 / 2}\right)$, an experimentally determined parameter. 


$$
k=\frac{\ln (2)}{t_{1 / 2}}
$$

From the work of Valitalo et-al reported half-life values for oxycodone depends on numerous factors. In healthy neonates it is about 4 hours, but can reach 8.8 hours in extremely preterm neonates. ${ }^{[5]}$ For healthy newborns, the half-life decreases to about 2.1 hours, a value that is approximately the same as that observed in healthy adults. ${ }^{[5]}$ Here we calculated $\mathrm{k}$ for all cases, from $\mathrm{t}_{1 / 2}=8.8$ to 2.1

With $\mathrm{k}$ in hand we used equation 2 to calculate the serum concentration of drug (oxycodone).

Urine concentration of oxycodone: As illustrated in Figure $\mathbf{S 6}$ the urine oxycodone concentration is found by estimating the fraction $\left(f_{m}\right)$ of oxycodone metabolized to noroxycodone and assuming the remaining oxycodone $\left(f_{r}\right)$ is found (excreted) in the urine. The rate of oxycodone elimination through urine $\left(\mathrm{dC}_{\mathrm{u}} / \mathrm{dt}\right)$ is therefore dependent upon the serum concentration $(C)$ and the renal clearance $\left(\mathrm{CL}_{\mathrm{r}}\right)$, and can expressed by equation 4:

$$
\frac{d C_{u}(t)}{d t}=f_{r} \cdot C L_{r} \cdot C(t)
$$

It should be noted that, the fraction of opioid eliminated through urine (not metabolized) is widely agreed upon to be $5-11 \%$ in adults. ${ }^{[8]}$ However, higher values have been reported for neonates, with some being as high $20 \%$. $^{5,9]}$ Here we chose to use a value $f_{r}=0.2$ based upon the published values for neonatal metabolite profiles. ${ }^{[10]}$ Because we did not consider other metabolites, in our calculation $f_{r}+$ $f_{m}=1$, this would make of $f_{m}=0.8$.

While few reports exist that quantify neonate metabolite profiles, there are indications that choosing a value of $10 \mathrm{~mL} / \mathrm{min} / \mathrm{kg}$ for renal clearance $\left(\mathrm{CL}_{r}\right)$, represents a relevant value. ${ }^{[9-11]}$ For subject weight we used $2 \mathrm{~kg}$ for a preterm neonate, $3.5 \mathrm{~kg}$ for a full-term neonate, and $7.2 \mathrm{~kg}$ for a 6 month old child. ${ }^{[12]}$ Using these body mass values we obtained opioid renal clearance values of $20 \mathrm{~mL} / \mathrm{min}$ for a preterm neonate, $35 \mathrm{~mL} / \mathrm{min}$ for a full-term neonate, and $72 \mathrm{~mL} / \mathrm{min}$ for a 6 month old.

To obtain the urine concentration of oxycodone as a function of time, (see Main Text Figure 5, blue line) we divide the oxycodone elimination rate determined by using equation 4 , by the rate of urine production. Here we used urine production rates of $0.5 \mathrm{~mL} / \mathrm{hr}$ for a preterm neonate and $1 \mathrm{~mL} / \mathrm{hr}$ for both a full-term neonate and a 6 month old child. ${ }^{[13]}$

\section{Conclusions:}

Here we demonstrate how improved sensitivity can positively impact both confirmatory testing of NAS and dose-titration for neonates undergoing pain management. Using a single-metabolite model for oxycodone metabolism and excretion, we put bounds on the expected range of lifetimes of both the drug and metabolite in serum and urine. In the pain-management setting, aptamer-based FSA-CIR would enable quantification of metabolite after a shorter period and therefore provide more accurate information for dosing.

\section{References}

[1] M. N. Kammer, A. K. Kussrow, I. R. Olmsted, D. J. Bornhop, ACS sensors 2018.

[2] aD. J. Bornhop, M. N. Kammer, A. Kussrow, R. A. Flowers, 2nd, J. Meiler, Proc Natl Acad Sci U S A 2016, 113, E1595-1604; bA. Kussrow, M. M. Baksh, D. J. Bornhop, M. G. Finn, Chembiochem : a European journal of chemical biology 2011, 12, 367-370.

[3] R. Nutiu, Y. Li, Angewandte Chemie 2005, 44, 1061-1065.

[4] J. B. Houston, G. Taylor, British journal of clinical pharmacology 1984, 17, 385-394.

[5] P. Valitalo, M. Kokki, V. P. Ranta, K. T. Olkkola, A. C. Hooker, H. Kokki, Pharm Res 2017, 34, $1125-1133$.

[6] G. M. Pacifici, Clinics 2016, 71, 474-480.

[7] M. M. Yazdy, R. J. Desai, S. B. Brogly, Journal of pediatric genetics 2015, 4, 56-70.

[8] R. Poyhia, T. Seppala, K. T. Olkkola, E. Kalso, British journal of clinical pharmacology 1992, 33, $617-621$.

[9] M. L. Pokela, E. Anttila, T. Seppala, K. T. Olkkola, Paediatric anaesthesia 2005, 15, 560-565. 
[10] M. Kokki, M. Heikkinen, P. Valitalo, H. Hautajarvi, J. Hokkanen, H. Pitkanen, U. Sankilampi, V. P. Ranta, H. Kokki, British journal of clinical pharmacology 2017, 83, 791-800.

[11] aH. Kokki, I. Rasanen, M. Reinikainen, P. Suhonen, K. Vanamo, I. Ojanpera, Clinical pharmacokinetics 2004, 43, 613-622; bT. Kart, L. L. Christrup, M. Rasmussen, Paediatric anaesthesia 1997, 7, 5-11; cE. Encinas, R. Calvo, J. C. Lukas, V. Vozmediano, M. Rodriguez, E. Suarez, Paediatric drugs 2013, 15, 247-257; dL. C. Ku, P. B. Smith, Pediatric research 2015, 77, 2-9; eP. J. Davis, R. L. Stiller, D. R. Cook, B. W. Brandom, K. A. Davin-Robinson, Anesthesia and analgesia 1988, 67, 268-271.

[12] H. H. Pomerance, Archives of pediatrics \& adolescent medicine 1997, 151, 324.

[13] M. D. Jones, Jr., E. L. Gresham, F. C. Battaglia, Biology of the neonate 1972, 21, 321-329.

[14] H. Kokki, I. Rasanen, M. Lasalmi, S. Lehtola, V. P. Ranta, K. Vanamo, I. Ojanpera, Clinical pharmacokinetics 2006, 45, 745-754.

[15] K. J. Anand, R. W. Hall, N. Desai, B. Shephard, L. L. Bergqvist, T. E. Young, E. M. Boyle, R. Carbajal, V. K. Bhutani, M. B. Moore, S. S. Kronsberg, B. A. Barton, N. T. I. Group, Lancet 2004, 363, 1673-1682. 